\title{
Molecular characterization and phylogenic analysis of Anaplasma spp. in small ruminants from Sulaymaniyah governorate, Iraq
}

\author{
S.H. Abdullah ${ }^{1} \odot$ and H.O. Dyary ${ }^{2} \odot$ \\ ${ }^{1}$ Department of Microbiology, ${ }^{2}$ Department of Basic Sciences, College of Veterinary Medicine, University of Sulaimani, \\ Sulaymaniyah, Iraq
}

\begin{tabular}{l} 
Article information \\
\hline Article history: \\
Received October 10, 2020 \\
Accepted January 01, 2021 \\
Available online October 11, 2021 \\
\hline Keywords: \\
Anaplasma \\
Goat \\
Sheep \\
PCR \\
Iraq \\
\hline
\end{tabular}

Correspondence:

H.O. Dyary

dyary.othman@univsul.edu.iq

\begin{abstract}
Anaplasma spp. are significant arthropod-borne bacteria globally, but documented information about anaplasmosis in small ruminants in the north of Iraq is insufficient. Hence, this study was conducted to determine the prevalence of Anaplasma spp. and identify sheep and goat tick vector populations in Sulaymaniyah Governorate, north Iraq. The study population consisted of 470 sheep and 145 goats from 45 livestock farms in 10 geographical locations of Sulaymaniyah Governorate. The study was accomplished from April to December 2017. Blood samples were taken from the jugular vein and used for DNA extraction. Polymerase chain reaction (PCR) was conducted using primers based on the $16 \mathrm{~S}$ rRNA of Anaplasma spp. Fragments of PCR products were sequenced for phylogenetic analysis. The prevalence of Anaplasma spp. was $58.9 \%$ based on the PCR results. Furthermore, $58.9 \%$ of sheep and $57.9 \%$ of goats were positive for anaplasmosis. The sequences represented $100 \%$ identity with previously documented GenBank isolates of $A$. ovis from Iran, the Netherlands, China, and Mongolia. Altogether, 150 Ixodid ticks were picked from small ruminants within the same flocks and were identified based on morphological features. Various infestation rates were observed; about $40 \%$ of the Ixodid ticks belonged to Rhipicephalus sanguineus, 34\% belonged to Rhipicephalus turanicus, $18 \%$ were Hyalomma anatolicum, and $8 \%$ were Boophilus microplus (Rhipicephalus microplus). The present report is the first molecular study of Anaplasma species in small ruminants from Sulaymaniyah Governorate in northern Iraq to the best of our knowledge. The study concluded that anaplasmosis was endemic in small ruminants from the investigated areas.
\end{abstract}

DOI: 10.33899/ijvs.2021.128475.1581, (CAuthors, 2022, College of Veterinary Medicine, University of Mosul.

This is an open access article under the CC BY 4.0 license (http://creativecommons.org/licenses/by/4.0/).

\section{Introduction}

Anaplasmosis is a widespread tick-borne disease that results in health problems negatively impacting the benefit of livestock (1). The genus Anaplasma includes obligate intracellular bacterial species that result in anaplasmosis in many animals and humans. Among Anaplasma spp. that impacted small ruminant health, A. bovis, A. marginale, A. ovis, and $A$. phagocytophilum were identified (2,3). Different Anaplasma spp. have diverse cell and host predilections. For example, A. platys infects canines' thrombocytes, while $A$. bovis largely parasitizes ruminants' monocytes (4). Anaplasma centrale, A. marginale, and A. ovis attack erythrocytes. Also, A. phagocytophilum infects human granulocytes (5).

Ovine and caprine anaplasmosis by $A$. ovis is widely distributed in different regions globally (6). Anaplasma ovis might result in chronic infection and, in some cases, hemolytic anemia with paleness and jaundice, with the absence of hemoglobinuria. Clinical signs include anorexia, 
a decrease in milk production, abortion, fever, and fatigue. However, the mortality rate is low (7). Anaplasma ovis has also been reported in tick vectors Rhipicephalus, Hyalomma, Dermacentor, and Ixodes (8). Anaplasma phagocytophilum is another cause of anaplasmosis in small ruminants that leads to tick-borne fever.

This species also infects other domestic animals such as cattle, horses, dogs, and cats (9). Ixodes spp., especially $I$. ricinus, are considered the primary tick vector for $A$. phagocytophilum. However, it was so detected in Dermacentor spp. (10). In ruminants, A. phagocytophilum causes inappetence, high fever, decreased milk yield, miscarriage, and immunosuppression, contributing to the development of secondary infections (11). Anaplasma bovis, A. centrale, and A. marginale have also been discovered in sheep and goats, indicating that they act as potential reservoirs of these organisms (12).

Most reports on A. ovis prevalence were from studies on clinically healthy animals. Nevertheless, A. ovis contagion could be severer in stressful conditions or the presence of other diseases (13). The lower productivity of local breeds of sheep could be associated with anaplasmosis, as they are easily exposed to stress and endemic pathogens (14).

Various studies on tick-borne hemoparasitic infections in sheep and goats were accomplished, while data about molecular identification of anaplasmosis is scarce. Hence, this study was conducted to determine the molecular characterization of anaplasmosis in small ruminants from Sulaymaniyah Governorate in the north of Iraq.

\section{Materials and methods}

\section{Study area, sample collection, and DNA extraction}

The study was carried out from April to December 2017, including 45 small ruminant farms from 10 different districts in Sulaymaniyah, Iraq, namely Arbat, Bakrajo, Bazian, Mawat, Nal Parez, Piramagroon, Sayid Sadiq, Sharazoor, Sitak, and Sulaimani. Six hundred fifteen animals, including 470 sheep and 145 goats, were selected randomly from different age groups older than one year.

Blood was taken from the jugular vein, collected in tubes with anticoagulants, and kept at $-20^{\circ} \mathrm{C}$ till DNA extraction. DNA was extracted using a specific commercial Kit from Genet Bio (South Korea) and kept at $-20^{\circ} \mathrm{C}$ till use.

\section{Polymerase chain reaction}

All DNA samples were tested using PCR with primer sets used in studies published previously. The forward primer 5'TACCTTGTTACGACTT- $3^{\prime}$ and reverse primer 5'TGATCCTGGCTCAGAACGAACG-3' were applied for amplification of the $1462 \mathrm{bp}$ portion of the $16 \mathrm{~S}$ rRNA gene of Anaplasma spp. $(15,16)$.

PCR reactions took place with a green master mix (2X) from GeNet Bio (South Korea) in a total volume of $20.0 \mu \mathrm{L}$.
The content included a $10.0 \mu \mathrm{L}$ master mix, $5.0 \mu \mathrm{L}$ DNA template, and 10.0 pmol from each sense and antisense primers. The final volume was completed with $3.0 \mu \mathrm{L}$ nuclear-free water, and amplification was done in a programmable thermal cycler (Prime, UK) with an initial denaturation of $5 \mathrm{~min}$ at $94^{\circ} \mathrm{C}$, followed by a three-step program. The program included $40-\mathrm{sec}$ denaturation at $94^{\circ} \mathrm{C}$, 35 -sec annealing at $55^{\circ} \mathrm{C}$, and $1.5 \mathrm{~min}$ extension at $72^{\circ} \mathrm{C}$ for a total of 40 cycles.

\section{Gel electrophoresis}

Following PCR amplification, the 1462-bp amplification product was loaded on a $1 \%$ agarose gel and stained with ethidium bromide (17). The electrophoresis was run at an electric current of 85 Volt for $65 \mathrm{~min}$, and a UV transilluminator projected them (Figure 1).

\section{DNA sequencing}

Five PCR products were randomly selected, three from sheep and two from goats, for sequencing, conducted by Sanger DNA Sequencing System in South Korea. The nucleotide sequence identities and resemblances were checked applying BLASTn analysis.

\section{Nucleotide sequence accession numbers}

The sequences were submitted in the GenBank database of NCBI (National Center for Biotechnology Information) by direct submission. The sequences were allotted accession numbers MT645478 to MT645482 for Anaplasma spp.

\section{Phylogenetic analysis}

The survey's sequences were equated with GenBank sequences of Anaplasma by phylogenetic analysis employing MEGA X (18). Maximum likelihood was applied to build phylogenetic trees for Anaplasma species-bootstrap analysis with a thousand replications to calculate the confidence of the nodes and branches of the trees.

\section{Tick collection and identification}

One hundred fifty ticks were detached carefully from different parts of the animal body, including adult and nymphal stages, using blunt forceps. Collected ticks were put in $70 \%$ ethanol (19), then labeled and brought to the laboratory. Adult ticks were morphologically distinguished to the species level under 40X magnification of a dissecting microscope. The identification of the tick genera was made according to Walker's keys and descriptions (20).

\section{Statistical analysis}

A Chi-squared test was applied to find an association between variables of animal spp. with Anaplasma infection. A probability value of $\leq 0.05$ was regarded as statistically significant. Statistical Package for Social Sciences (SPSS) version 19.0 (IBM, USA) was used. 


\section{Results}

Analysis of 615 blood samples of small ruminants with PCR revealed that $58.7 \% \quad(n=361)$ were infected with Anaplasma spp. The prevalence rates of anaplasmosis were as follows: $58.9 \%$ of the total 470 examined sheep were positive for Anaplasma spp., whereas 84 of 145 goats $57.9 \%$ were positive for anaplasmosis. No statistically significant difference in the rates of anaplasmosis occurrence was present between sheep and goats $(\mathrm{P}>0.05)$.

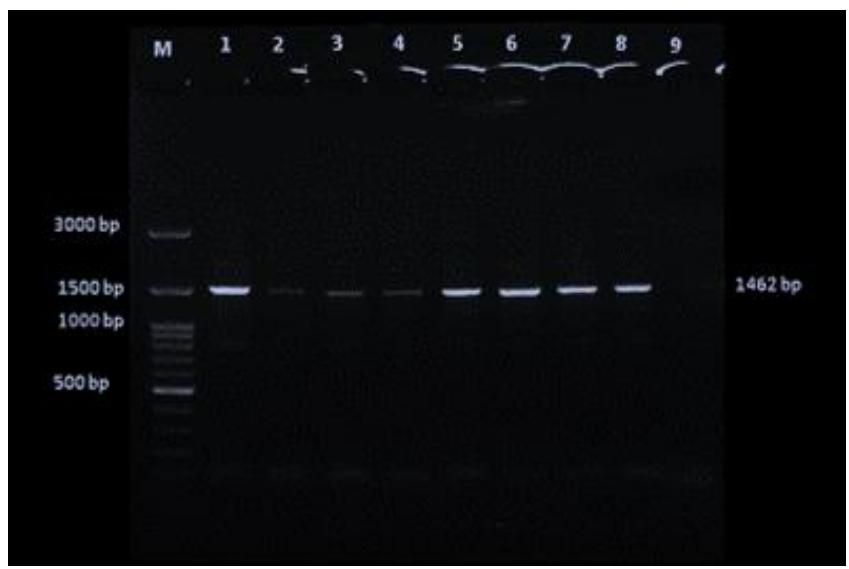

Figure 1: Agarose gel electrophoresis of amplified products of Anaplasma spp. stained with ethidium bromide. Lane M revealed a 100-bp DNA ladder. Lanes 1-8 were the positive samples for Anaplasma species, and lane 9 is the negative control. The large size of the bands may be related to the presence of large amounts of DNA.

All DNA sequences showed high similarity with previously registered Anaplasma spp. in the GenBank database (Figure 2). The sequences showed 100\% identity with the A. ovis isolates with accession no. JF514506 and JF514512 from Iran, also AF318945, KX579073, MG869525, and LC194134 from the Netherlands, China, and Mongolia, respectively. Also, the identity of Anaplasma spp. new isolates with $A$. phagocytophilum reported isolates were $96.0 \%$ similar with isolates MN611755 and MN611756 from Turkey; $96.8 \%$ and $97.3 \%$ with isolates KJ782387 and KX272641 from China, respectively.

The phylogenetic tree constructed based on the $16 \mathrm{~S}$ rRNA gene of Anaplasma species revealed that the isolates from Sulaymaniyah Governorate were clustered together. They represented a close resemblance and laid in a clade with previously reported $A$. ovis isolates from sheep and goats in Iraq, Iran, China, Mongolia, and the Netherlands. Additionally, Anaplasma new isolates were clustered separately with A. ovis isolates KC778788 and KC778789 from northern Iraq, with homologies between $99.6 \%$ and $100.0 \%$ (Figure 2).
The identified collected ticks belonged to Hyalomma anatolicum, Rhipicephalus sanguineus, Rhipicephalus turanicus, and Boophilus microplus (Rhipicephalus microplus), with various infestation rates. Of the 150 collected Ixodid ticks, 60 tick samples (40\%) were identified as Rhipicephalus sanguineus, and 51 samples (34\%) were Hayaloma anatolicum. Also, 27 samples (18\%) were identified as Rhipicephalus turanicus, and 12 ticks (8\%) belonged to Boophilus microplus (Rhipicephalus microplus). The dataset represented a high level of infestation of small ruminants with Rhipicephalus spp. ticks.

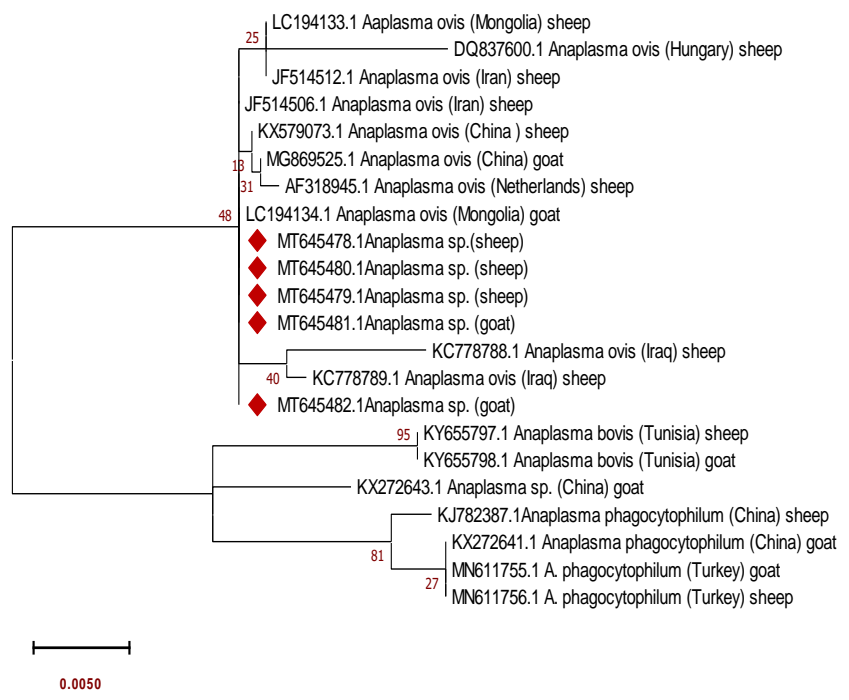

Figure 2: Phylogenetic tree constructed using the 16S rRNA gene of Anaplasma spp. The tree was constructed with the maximum likelihood method Kimura 2-parameter model and bootstrap test of 1000 replications using MEGA X. The study's sequences are marked with red diamonds.

\section{Discussion}

Anaplasmosis is a significant problem for small ruminants that frequently occurs in tropical and subtropical regions (21). About 58.7\% $(n=361)$ of examined samples were positive for Anaplasma spp. by PCR assay. Following our findings, high prevalence rates of small ruminant anaplasmoses were also reported by PCR in Iran (22), Turkey (23), and Saudi Arabia (24). However, lower prevalence rates of $40.8 \%$ and $29.3 \%$ were reported in Kenya (25) and Pakistan (26).

The present study is consistent with previous reports, in which a higher rate of anaplasmosis was reported in sheep than in goats. Shabana et al. (24) found that the prevalence was $25.3 \%$ in sheep and $15.5 \%$ in goats, using PCR assay. Also, prevalence rates of $32.0 \%$ and $25.3 \%$ were reported in sheep and goats, respectively, by Ghaffar et al. (26). However, Eisawi et al. (27) found a higher prevalence of 
$35.9 \%$ among goats than sheep, $32.5 \%$. Also, prevalence rates of $34.7 \%$ from goat and $21.8 \%$ from sheep were reported by Yousefi et al. (3).

Based on previous studies, $A$. ovis was the most prevalent species among small ruminants $(28,29)$. Furthermore, $A$. phagocytophilum was reported at various prevalence rates in different geographical areas. A prevalence of $4.7 \%$ was reported in the middle region of Iraq by Hamzah and Hasso (30). In Turkey, prevalence rates of $8.51 \%$ and $1.08 \%$ were also reported $(31,32)$. However, infection rates as high as $28.8 \%$ and $66.7 \%$ were reported from other regions such as China and Turkey $(33,34)$.

The phylogenetic analysis of obtained Anaplasma nucleotide sequences from the current study in sheep and goats revealed that the isolates shared $100 \%$ identity with GenBank isolates of Anaplsama ovis from Iran with accession numbers JF514506 and JF514512, also with isolates AF318945, KX579073, MG869525, and LC194134 from the Netherlands, China and Mongolia, respectively. New Anaplasma spp. isolates were clustered separately with the isolate KC778788 and KC778789 from northern Iraq. The new isolates were $96.0 \%$ identical with $A$. phagocytophilum isolates MN611755 and MN611756 from Turkey. They were $96.8 \%$ and $97.3 \%$ identical with isolates KJ782387 and KX272641 from China.

The identified collected tick from examined sheep and goats within the same small ruminant flocks belonged to Hyalomma anatolicum, Rhipicephalus sanguineus, Rhipicephalus turanicus, and Boophilus microplus (Rhipicephalus microplus), with various infestation rates of $18.0 \%, 40.0 \%, 34.0 \%$, and $8.0 \%$ for each identified tick species respectively. So, the dataset represented a high level of small ruminant's infestation with Rhipicephalus spp. ticks.

Rhipicephalus sanguineus was recognized as being the most predominant species collected from small ruminants. $R$. sanguineus is regarded as a worldwide distributed tick and can convey pathogens such as Anaplasma spp., Coxiella burnetii, Ehrlichia spp., and Rickettsia rickettsii $(35,36)$.

Rhipicephalus sanguineus is identified as a common transmitter for Anaplasma spp., documented from different geographical areas (37). By molecular study, the A. ovis genome was detected from $R$. sanguineus ticks. Furthermore, $A$. ovis has also been detected from $R$. turanicus (8) by molecular assay. This study is considered the first molecular investigation of anaplasmosis in north Iraq. A previous study (38) investigated Anaplasma ovis prevalence in angora goats in Duhok, north Iraq. However, the researcher used cELISA in the study.

\section{Conclusion}

This study disclosed a high infection rate of Anaplasma spp. in small ruminants from the Sulaymaniyah governorate of Iraq. However, sampled animals had no apparent clinical signs, indicating that anaplasmosis was endemic in small ruminants with a subclinical pattern. Sequence analysis revealed that new Anaplasma sequence isolates were $100 \%$ identical with A. ovis isolates from the GenBank database. The identified collected ticks from study areas belonged to different species with higher infestation rates with Rhipicephalus spp. The findings will be useful as baseline data for further study about different Anaplasma species and identifying their tick vectors.

\section{Conflict of interest}

The authors declare no conflict of interest.

\section{Acknowledgment}

The University of Sulaimani financially supported this study. The authors acknowledge the veterinarians' assistance at the Directorate of Veterinary Services in Sulaymaniyah during the sampling.

\section{References}

1. Aouadi A, Leulmi H, Boucheikhchoukh M, Benakhla A, Raoult D, Parola P. Molecular evidence of tick-borne hemoprotozoan-parasites (Theileria ovis and Babesia ovis) and bacteria in ticks and blood from small ruminants in Northern Algeria. Comp Immunol Microbiol Infect Dis. 2017;50:34-39. Doi: 10.1016/j.cimid.2016.11.008

2. Belkahia H, Said MB, El Mabrouk N, Saidani M, Cherni C, Hassen MB, Bouattour A, Messadi L. Seasonal dynamics, spatial distribution and genetic analysis of Anaplasma species infecting small ruminants from northern Tunisia. Infect Genet Evol. 2017;54:66-73. DOI: 10.1016/j.meegid.2017.06.016

3. Yousefi A, Rahbari S, Shayan P, Sadeghi-dehkordi Z, Bahonar A. Molecular detection of Anaplasma marginale and Anaplasma ovis in sheep and goat in west highland pasture of Iran. Asian Pac J Trop Biomed. 2017;7:455-459. DOI: 10.1016/j.apjtb.2017.01.017

4. Goethert HK, Telford SR. Enzootic transmission of Anaplasma bovis in Nantucket cottontail rabbits. J Clin Microbiol. 2003;41:3744-3747. DOI: 10.1128/JCM.41.8.3744-3747.2003

5. Rikihisa Y. Mechanisms of obligatory intracellular infection with Anaplasma phagocytophilum. Clin Microbiol Rev. 2011;24:469-489. DOI: 10.1128/CMR.00064-10

6. Wang Z, Yang J, Niu Q, Brayton KA, Luo J, Liu G, Yin H, Liu Z. Identification of Anaplasma ovis appendage-associated protein (AAAP) for development of an indirect ELISA and its application. Parasit Vectors. 2017;10:359. DOI: 10.1186/s13071-017-2297-Z

7. Stuen S, Longbottom D. Treatment and control of chlamydial and rickettsial infections in sheep and goats. Vet Clin North Am Small Anim Pract. 2011;27:213-233. DOI: 10.1016/j.cvfa.2010.10.017

8. Song R, Wang Q, Guo F, Liu X, Song S, Chen C, Tu C, Wureli H, Wang Y. Detection of Babesia spp., Theileria spp. and Anaplasma ovis in border regions, northwestern China. Transbound Emerg Dis. 2018;65:1537-1544. DOI: 10.1111/tbed.12894

9. Poitout FM, Shinozaki JK, Stockwell PJ, Holland CJ, Shukla SK. Genetic variants of Anaplasma phagocytophilum infecting dogs in Western Washington State. J Clin Microbiol. 2005;43:796-801. DOI: 10.1128/JCM.43.2.796-801.2005

10. Milner JM, van Beest FM. Ecological correlates of a tick-borne disease, Anaplasma phagocytophilum, in moose in southern Norway. Eur J Wildl Res. 2013;59:399-406. DOI: 10.1007/s10344-012-0685-4

11. Woldehiwet Z. Immune evasion and immunosuppression by Anaplasma phagocytophilum, the causative agent of tick-borne fever 
of ruminants and human granulocytic anaplasmosis. Vet $\mathrm{J}$. 2008;175:37-44. DOI: 10.1016/j.tvj1.2006.11.019

12. da Silva NB, Taus NS, Johnson WC, Mira A, Schnittger L, Valente JD, Vidotto O, Masterson HE, Vieira TS, Ueti MW. First report of Anaplasma marginale infection in goats, Brazil. Brazil. PloS One. 2018;13:e0202140. DOI: 10.1371/journal.pone.0202140

13. Maharana BR, Tewari AK, Saravanan BC, Sudhakar NR. Important hemoprotozoan diseases of livestock: Challenges in current diagnostics and therapeutics: An update. Vet World. 2016;9:487. DOI: 10.14202/vetworld.2016.487-495

14. Bilgic HB, Bakırcı S, Kose O, Unlu AH, Hacılarlıoglu S, Eren H, Weir $\mathrm{W}$, Karagenc T. Prevalence of tick-borne haemoparasites in small ruminants in Turkey and diagnostic sensitivity of single-PCR and RLB. Parasit Vectors. 2017;10:211. DOI: 10.1186/s13071-017-2151$\underline{3}$

15. Kawahara M, Rikihisa $\mathrm{Y}$, Lin $\mathrm{Q}$,Isogai E, Tahara K, Itagaki A, Hiramitsu Y, Tajima T. Novel genetic variants of Anaplasma phagocytophilum, Anaplasma bovis, Anaplasma centrale, and a novel Ehrlichia sp. in wild deer and ticks on two major islands in Japan. Appl Environ Microbiol. 2006;72:1102-1109. DOI: 10.1128/AEM.72.2.1102-1109.2006

16. Alfatlawi MA, Jasim AA, Jarad NE, Khlaif S. Clinical and molecular identification of ruling Theileria annulata strains in cattle calves in Al-Diwaniyah province, Iraq. Iraqi $\mathrm{J}$ Vet Sci;2020. DOI: 10.33899/ijvs.2020.126429.1319

17. Ismael S, Omer LT. Molecular identification of new circulating Hyalomma asiaticum asiaticum from sheep and goats in Duhok governorate, Iraq. Iraqi J Vet Sci. 2020. DOI: 10.33899/ijvs.2020.126330.1298

18. Kumar S, Stecher G, Li M, Knyaz C, Tamura K. MEGA X: molecular evolutionary genetics analysis across computing platforms. Mol Biol Evol. 2018;35:1547-1549. DOI: 10.1093/molbev/msy096

19. Mustafa B. Detection on ectoparasites on small ruminants and their impact on the tanning industry in Sulaimani province. Iraqi J Vet Sci. 2019;33:303-309. DOI: 10.33899/ijvs.2019.162995

20. Walker AR, Ticks of domestic animals in Africa :a guide to identification of species. Bioscience Reports, Edinburgh: 2003. 227 p. Available at: [available here]

21. Ros-García A, Barandika JF, García-Pérez AL, Juste RA, Hurtado A. Assessment of exposure to piroplasms in sheep grazing in communal mountain pastures by using a multiplex DNA bead-based suspension array. Parasit Vectors. 2013;6:1-11. DOI: 10.1186/1756-3305-6-277

22. Khaki Z, Jalali SM, Kazemi B, Razi Jalali M, Yasini SP. A study of hematological changes in sheep naturally infected with Anaplasma spp. and Theileria ovis: Molecular diagnosis. Iran $\mathrm{J}$ Vet Med. 2015;9:19-26. DOI: 10.22059/IJVM.2015.53228

23. Altay K, Dumanli N, Aktas M, Ozubek S. Survey of Anaplasma infections in small ruminants from East part of Turkey. Kafkas Univ Vet Fak Derg. 2014;20:1-4. DOI: 10.9775/kvfd.2013.9189

24. Shabana I, Alhadlag N, Zaraket H. Diagnostic tools of caprine and ovine anaplasmosis: a direct comparative study. BMC Vet Res. 2018;14:165. DOI: $10.1186 / \mathrm{s} 12917-018-1489-\mathrm{x}$

25. Ringo AE, Aboge GO, Moumouni PFA, Lee SH, Jirapattharasate C, Liu M, Gao Y, Guo H, Zheng W, Efstratiou A. Molecular detection and genetic characterisation of pathogenic Theileria, Anaplasma and Ehrlichia species among apparently healthy sheep in central and western Kenya. Onderstepoort J Vet Res. 2019;86:1-8. DOI: 10.4102/ojvr.v86i1.1630

26. Ghaffar A, Ijaz M, Ali A, Farooqi SH, Rehman A, Ali MM, Zafar MZ, Naeem MA. First report on molecular characterization of anaplasmosis in small ruminants in Pakistan. $\mathrm{J}$ Parasitol. 2020;106:360-368. DOI: $10.1645 / 19-90$

27. Eisawi NM, El Hussein ARM, Hassan DA, Musa AB, Hussien MO, Enan KA, Bakheit MA. A molecular prevalence survey on Anaplasma infection among domestic ruminants in Khartoum State, Sudan. Trop Anim Health Prod. 2020;1-8. DOI: 10.1007/s11250-019-02176-7

28. Hakimi H, Sarani A, Takeda M, Kaneko O, Asada M. Epidemiology, risk factors, and co-infection of vector-borne pathogens in goats from
Sistan and Baluchestan province, Iran. PloS One. 2019;14:e218609. DOI: 10.1371/journal.pone.0218609

29. Goudarzi G, Tavakoli M, Ezatpour B, Kooshki H, Hosseini-Chegeni A. Molecular detection of Theileria ovis (Apicomplexa: Theileriidae), Anaplasma ovis (Rickettsiales: Anaplasmataceae), and Mycoplasma sp. (Tenericutes: Mycoplasmataceae) from sheep blood in western Iran. Comp Clin Path. 2019;28:1661-1666. DOI: 10.1007/s00580019-02995-y

30. Hamzah KJ, Hasso SA. Molecular prevalence of Anaplasma phagocytophilum in sheep from Iraq. Open Vet J. 2019;9:238-245. DOI: 10.4314 /ovj.v9i3.8

31. Öter K, Cetinkaya H, VURUŞANER C, Toparlak M, Ergünay K. Molecular detection and typing of Anaplasma species in small ruminants in Thrace region of Turkey. Kafkas Uni Vet Fak Derg. 2015;22:133-138. DOI: $10.9775 / \mathrm{kvfd} .2015 .14075$

32. Yousefi A ,Rahbari S, Shayan P, Sadeghi-dehkordi Z, Bahonar A. Molecular evidence of Anaplasma phagocytophilum: an emerging tick-borne pathogen in domesticated small ruminant of Iran; first report. Comp Clin Path. 2017;26:637-642. DOI: 10.1007/s00580-0172429-Z

33. Yang J, Li Y, Liu Z, Liu J, Niu Q, Ren Q, Chen Z, Guan G, Luo J, Yin $\mathrm{H}$. Molecular detection and characterization of Anaplasma spp. in sheep and cattle from Xinjiang, northwest China. Parasit Vectors. 2015;8:108. DOI: 10.1186/s13071-015-0727-3

34. Benedicto B, Ceylan O, Moumouni PFA, Lee SH, Tumwebaze MA, Li J, Galon EM, Liu M, Li Y, Ji S. Molecular detection and assessment of risk factors for tick-borne diseases in sheep and goats from Turkey. Acta Parasitol. 2020; 65: 723-732. DOI: 10.2478/s11686-020-00207$\underline{0}$

35. Dantas-Torres F. The brown dog tick, Rhipicephalus sanguineus (Latreille, 1806)(Acari: Ixodidae): from taxonomy to control. Vet Parasitol. 2008;152:173-185. DOI: 10.1016/j.vetpar.2007.12.030

36. Sarih MH, M'Ghirbi Y, Bouattour A, Gern L, Baranton G, Postic D. Detection and identification of Ehrlichia spp. in ticks collected in Tunisia and Morocco. J Cli Microbiol. 2005;43:1127-1132. DOI: 10.1128/JCM.43.3.1127-1132.2005

37. Stafford KC. Tick Management Handbook; an integrated guide for homeowners, pest control operators, and public health officials for the prevention of tick-associated disease. Connecticut: The Connecticut Agricultural Experiment Station; 2004. 71 p. [available here]

38. Naqid I. Prevalence of Anaplasma ovis infection in Angora goats of Duhok province, Iraq. I Iraqi J Vet Sci. 2017;31:73-79. DOI: 10.33899/ijvs.2017.145599
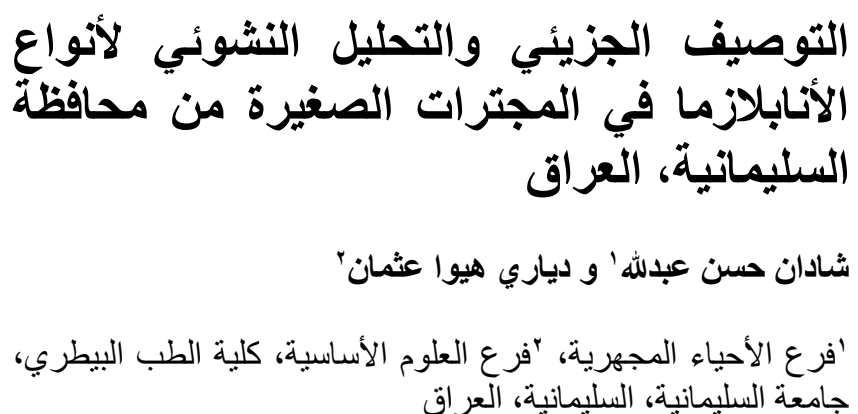

الخلاصة

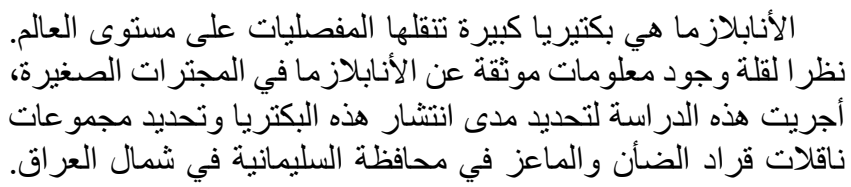




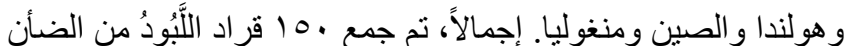

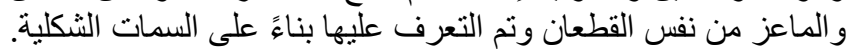

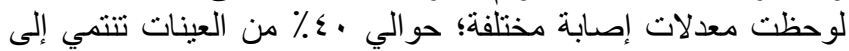

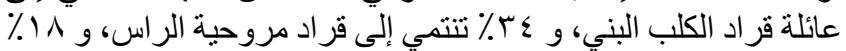

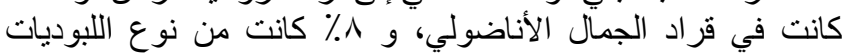

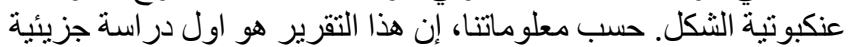

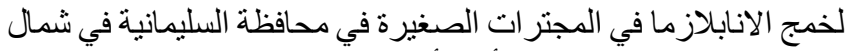

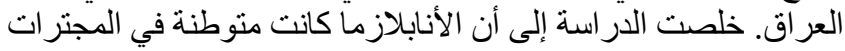
الصغيرة من المناطق التي تم فحصها.

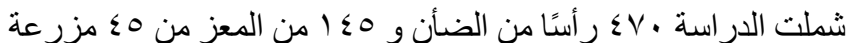

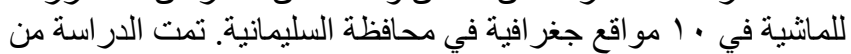

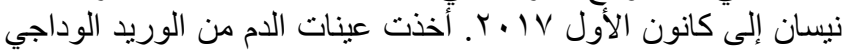

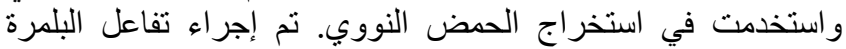

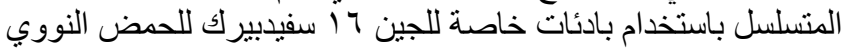

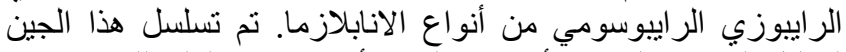

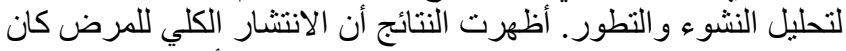

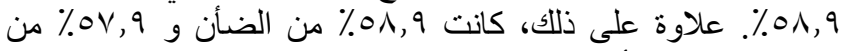

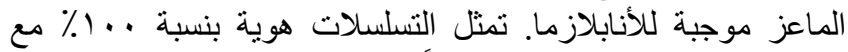
عزلات بنك الجينات الموثقة سابقاً إلى الانابلازما البقرية من إيران 